\title{
Utilisation des graines protéagineuses dans l'alimentation de la chèvre en début de lactation
}

\author{
C. MASSON \\ avec la collaboration technique de F. Delamarche et F. Faurie \\ I.N.R.A., Laboratoire de recherches de la Chaire de Zootechnie \\ E.N.S.S.A.A., 26, bd Docteur-Petitjean, F 21000 Dijon
}

\begin{abstract}
Résumé
Trente-deux chèvres réparties en quatre lots sont utilisées pour étudier le remplacement du soja par des graines protéagineuses (féverole, pois et lupin) dans l'alimentation de la chèvre en début de lactation.

Les niveaux d'ingestion de fourrage et de concentré sont en moyenne respectivement de 1500 et $948 \mathrm{~g}$ de MS par jour; il n'existe pas de différence significative de consommation entre les quatre concentrés. La production laitière journalière est de $3,47 \mathrm{~kg}$ par jour; la composition du lait est peu affectée par la nature de la complémentation azotée, seul le taux butyreux du lot «féverole» diffère significativement $(p<0,05)$. Les autres taux butyreux et les taux azotés sont semblables.
\end{abstract}

\section{1. - Introduction}

Dans un contexte de pénurie croissante de matières premières, l'utilisation des graines protéagineuses riches en protéines (pois, féverole et lupin) est intéressante pour les monogastriques mais aussi pour les ruminants présentant des potentiels de production élevés. A ce sujet, diverses études ont été conduites chez les animaux en croissance, agneaux, veaux et taurillons (Giovanni, Guilhermet \& Toullec, 1975 ; Hill \& Arnold, 1975 ; Sharma \& Nicholson, 1975 ; Cazes, 1978 ; TisSERAND, 1978 ; TisSERAND \& LaWrENCE, 1979). En revanche, peu d'études ont été réalisées chez des femelles laitières (Ingalls \& McKirdy, 1974; Pelletier \& BouCHARD, 1978 ; Tisserand, 1978). De ce fait, il nous est apparu intéressant d'étudier la substitution de ces graines protéagineuses au tourteau de soja dans l'alimentation de la chèvre en raison du haut potentiel laitier de cet animal. L'expérience a été réalisée en début de lactation puisqu'à ce stade de lactation les besoins en protéines sont les plus élevés. 


\section{2. - Matériel et méthodes}

\section{Animaux}

32 chèvres multipares de race Alpine sont réparties en quatre lots homogènes en fonction du poids vif, du numéro de lactation et du niveau de production laitière de l'année précédente. Le lot témoin $\mathrm{T}$ reçoit comme source azotée dans le concentré du soja, le lot $\mathrm{F}$ de la féverole (variété Ascott), le lot $\mathrm{P}$ du pois (variété Amino) et le lot $\mathrm{L}$ du lupin blanc.

\section{Aliments}

Tous les animaux reçoivent dès la $4^{\mathrm{e}}$ semaine avant la date présumée de la misebas le foin expérimental de dactyle-luzerne à volonté dont la valeur énergétique moyenne est $0,65 \mathrm{UFL} / \mathrm{kg}$ MS et la valeur azotée $92 \mathrm{~g} \mathrm{MAD} / \mathrm{kg}$ MS et $400 \mathrm{~g} \mathrm{MS}$ de concentré expérimental. Les concentrés (orge + sources azotées) sont iso-énergétiques et iso-azotés (voir tableau 1) et distribués selon le plan suivant :

\begin{tabular}{c|cccccccc}
\hline \hline $\begin{array}{c}\text { Semaine par rapport à la mise- } \\
\text { bas } \ldots \ldots \ldots \ldots \ldots \ldots \ldots \ldots\end{array}$ & -4 & -3 & -2 & -1 & 0 & +1 & +2 & $+3 \ldots$ \\
\hline $\begin{array}{r}\text { Quantité de concentré }(\mathrm{g}) \text { distri- } \\
\text { buée par jour .......... }\end{array}$ & 400 & 400 & 400 & 600 & 600 & 800 & 1000 & 1000 \\
\hline
\end{tabular}

Au-delà de la $3^{\text {e }}$ semaine après la mise-bas, le concentré est distribué à raison de $350 \mathrm{~g} / \mathrm{kg}$ de lait au-dessus d'une production supérieure à $4 \mathrm{~kg}$ de lait.

\section{3. - Mesures}

\section{Alimentation}

Les quantités ingérées de matière sèche de foin sont mesurées individuellement avec précision pendant trois jours consécutifs les $-2^{\mathrm{e}},+1^{\mathrm{re}}, 3^{\mathrm{e}}, 5^{\mathrm{e}}, 7^{\mathrm{e}}, 9^{\mathrm{e}}$ et $11^{\mathrm{e}}$ semaines. Les quantités ingérées de concentré sont mesurées tous les jours pendant les onze semaines expérimentales.

\section{Lait}

La production laitière est pesée à chaque traite pendant cinq jours par semaine. Les taux butyreux (méthode Gerber) et azoté (méthode Kjeldahl) sont mesurés pour chaque chèvre une fois par semaine sur un échantillon prélevé sur deux traites consécutives (soir et matin). 
Tableau 1

Composition chimique et valeur nutritive des aliments

Chemical composition and nutritive value of feeds

\begin{tabular}{|c|c|c|c|c|c|c|}
\hline $\begin{array}{c}\text { Aliment } \\
\text { Feed }\end{array}$ & $\begin{array}{c}\text { Cendres } \\
\% \text { M.S. } \\
\text { Ash } \\
\% \text { D.M. }\end{array}$ & $\begin{array}{c}\text { Matières } \\
\text { azotées } \\
\text { \% M.S. } \\
\text { Crude } \\
\text { Protein } \\
\% \text { D.M. }\end{array}$ & $\begin{array}{l}\text { Cellulose } \\
\text { Weende } \\
\text { \% M.S. } \\
\text { Crude Fibre } \\
\text { \% D.M. }\end{array}$ & $\begin{array}{c}\text { Matières } \\
\text { grasses } \\
\% \text { M.S. } \\
\text { Fat } \\
\% \text { D.M. }\end{array}$ & $\begin{array}{l}\text { U.F.L. } \\
\text { par kg } \\
\text { M.S. } \\
\text { Feed Unit } \\
\text { per kg } \\
\text { D.M. }\end{array}$ & $\begin{array}{c}\text { M.A.D. } \\
\text { g/kg } \\
\text { M.S. } \\
\text { D.C.P. } \\
\text { g/kg } \\
D . M .\end{array}$ \\
\hline $\begin{array}{l}\text { Concentré } \mathrm{T} \ldots \\
\text { Concentrate }\end{array}$ & 6,3 & 19,7 & 4,9 & 2,6 & 1,10 & 159 \\
\hline Concentré $F$ & 5,4 & 18,5 & 6,1 & 2,3 & 1,09 & 146 \\
\hline Concentré $\mathrm{P}$ & 6,1 & 17,8 & 4,7 & 2,8 & 1,10 & 141 \\
\hline Concentré L & 5,3 & 18,2 & 6,4 & 4,6 & 1,11 & 144 \\
\hline $\begin{array}{l}\text { Foin } \\
\text { Hay }\end{array}$ & 8,8 & 13,8 & 37,4 & - & 0,65 & 92 \\
\hline
\end{tabular}

Poids

Les chèvres sont pesées une fois par semaine à jour et heure fixes.

\section{4. - Résultats - Discussion}

1) Quantités ingérées (voir figure 1)

La consommation totale de matière sèche des chèvres a peu varié en fonction de la source azotée du concentré. Les aliments concentrés expérimentaux sont bien acceptés, la consommation moyenne journalière durant les onze premières semaines de lactation est respectivement de $1015,836,957$ et $985 \mathrm{~g}$ de MS pour les lots $\mathrm{T}$, $F, P$ et $L$. La source azotée n'influence pas significativement le niveau d'ingestion, ce qui confirme nos premières observations sur des chèvres en milieu de lactation (MASson, 1981) ; la consommation moindre du lot $\mathrm{F}$ est due à une distribution plus faible au-delà de la $5^{\mathrm{e}}$ semaine par suite d'un niveau de production laitière plus faible et d'une consommation de foin plus importante. Le niveau d'ingestion journalier de foin est bon, il est en moyenne de $1567,1640,1366$ et $1440 \mathrm{~g}$ de MS respectivement pour les lots $T, F, P$ et $L$, ce qui représente $60,7,66,3,58,9$ et 59,4 p. cent de la consommation totale de matière sèche. 

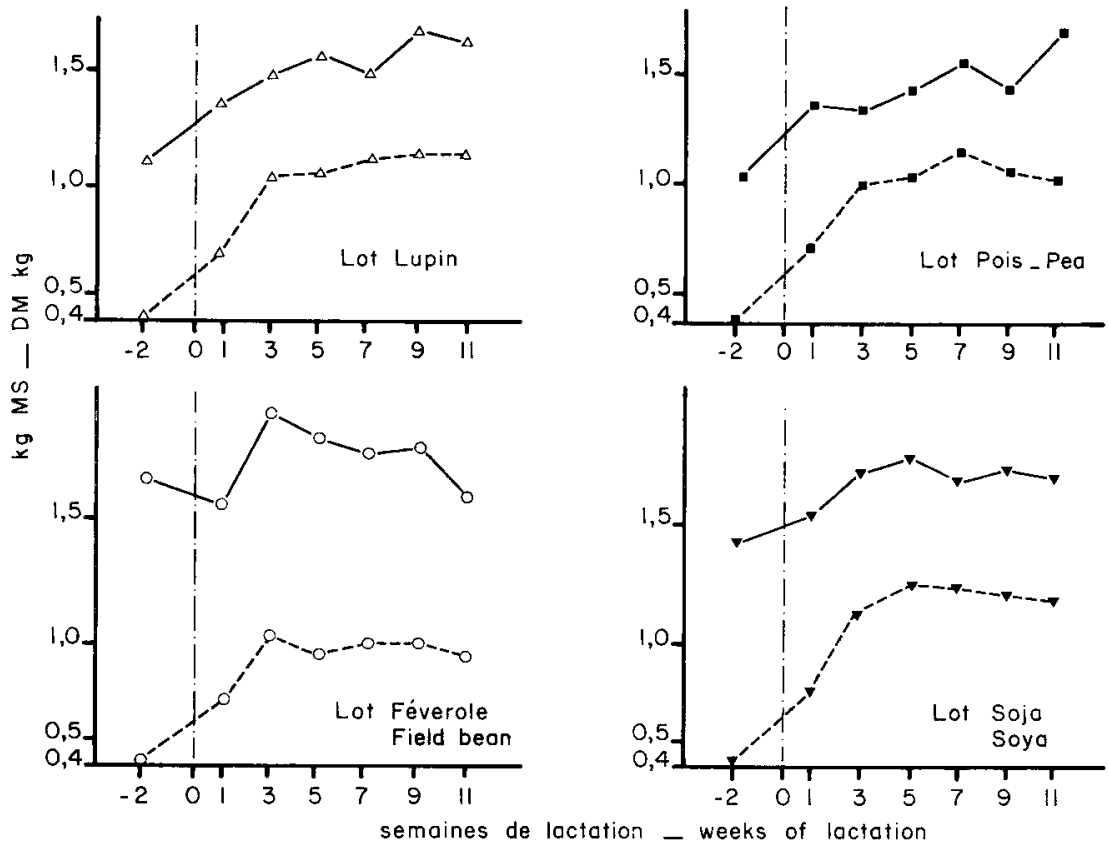

FIG. 1

Evolution des quantités de matière sèche ingérées de foin (-) et de concentré (--) Variations in forage (-) and concentrate (--) dry matter voluntary intake

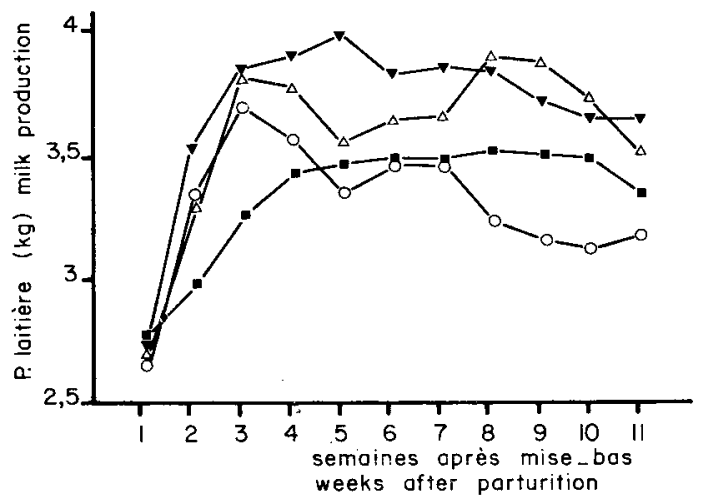

FIG. 2

Evolution de la production laitière (P.L. en $\mathrm{kg} /$ jour) Variation in milk production $(\mathrm{kg} /$ day) 


\section{2) Production laitière}

Durant les onze premières semaines de lactation, la production laitière journalière moyenne par chèvre est pour l'ensemble des quatre lots de $3,47 \pm 0,95 \mathrm{~kg}$ (voir figure 2). La nature de la complémentation azotée n'influence pas significativement la production laitière des chèvres; elle est de $3,67,3,28,3,34$ et $3,58 \mathrm{~kg}$ par jour respectivement pour les lots $\mathrm{T}, \mathrm{F}, \mathrm{P}$ et $\mathrm{L}$. Toutefois, comme le montre la figure 2 , la féverole et le pois ont tendance à être moins favorables que le lupin et le soja pour la production laitière, phénomène déjà observé précédemment (Masson, 1981) notamment pour la féverole.

L'évolution de la production laitière après la mise-bas n’est pas la même suivant les lots; pour les lots $\mathrm{T}, \mathrm{F}$ et $\mathrm{L}$ après un niveau de départ semblable respectivement de $2,72,2,65$ et $2,71 \mathrm{~kg}$ par jour durant la première semaine, la production laitière augmente rapidement pour atteindre, dès la $3^{\circ}$ semaine, un maximum qui va se maintenir jusqu'à la onzième semaine pour les lots $T$ et $L$ alors que pour le lot $F$ la production va diminuer sensiblement. Pour les chèvres du lot $\mathrm{P}$, la production laitière semblable aux autres lots $\mathrm{la}^{\mathrm{re}}$ semaine $(2,77 \mathrm{~kg}$ par jour) augmente régulièrement pour n'atteindre son maximum quaux alentours de la $7^{\circ}$ semaine. Cette différence dépend certainement plus de la constitution des lots que de la nature du régime ou de l'adaptation au régime puisque tous les animaux ont reçu le concentré expérimental dès la quatrième semaine avant la mise-bas.

\section{3) Composition du lait}

La composition du lait est sensiblement modifiée par la nature de la complémentation azotée (voir figure 3). Ainsi, le taux butyreux moyen au cours des onze premières semaines de lactation diffère de façon significative $(p<0,05)$ en fonction des lots. Le taux butyreux du lot $F(30,2 \mathrm{~g} / \mathrm{kg})$ est significativement inférieur au taux butyreux des lots : $\mathrm{P}(35,1 \mathrm{~g} / \mathrm{kg}), \mathrm{S}(35,9 \mathrm{~g} / \mathrm{kg})$ et $\mathrm{L}(37,0 \mathrm{~g} / \mathrm{kg})$. La supériorité du taux butyreux du lait obtenu avec la complémentation en lupin avait déjà été observée en milieu de lactation pour la chèvre (MASSON, 1981); elle peut certainement être attribuée à la teneur en matières grasses plus élevée du lupin (voir tableau 1). Par ailleurs, ces résultats concordent avec les observations de Pelletier \& BouCHARD (1978) qui, chez la vache laitière, notent que, par rapport au soja, la féverole et le pois ne modifient pas la teneur en matières grasses du lait.

Les taux azotés moyens ne diffèrent pas significativement en fonction des lots (voir figure 3) ; ils sont respectivement de $34,1,33,0,32,3$ et $34,2 \mathrm{~g} / \mathrm{kg}$ pour les lots $\mathrm{T}, \mathrm{F}, \mathrm{P}$ et $\mathrm{L}$.

Les variations des taux butyreux et des taux azotés durant les onze premières semaines de lactation sont les mêmes pour les quatre lots et semblables à celles décrites par ailleurs (MORAND-FEHR, 1978), à savoir une diminution importante des taux butyreux et azotés au cours des trois premières semaines de lactation.

Tous ces phénomènes sont à rapprocher du bilan énergétique (voir figure 4) qui, calculé en soustrayant les besoins des apports, a été négatif jusqu’à la $7^{\circ}$ semaine de lactation mais surtout jusquà la $3^{*}$ ' semaine (-0,3 UF). 

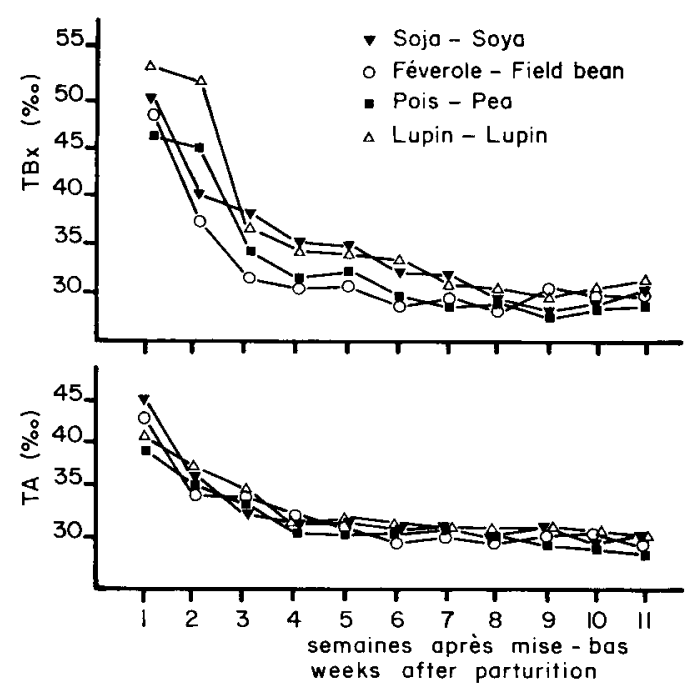

FIG. 3

Evolution du taux butyreux (TBx) et du taux azoté (TA) du lait Variation in milk fat (TB.x) and protein content (TA)

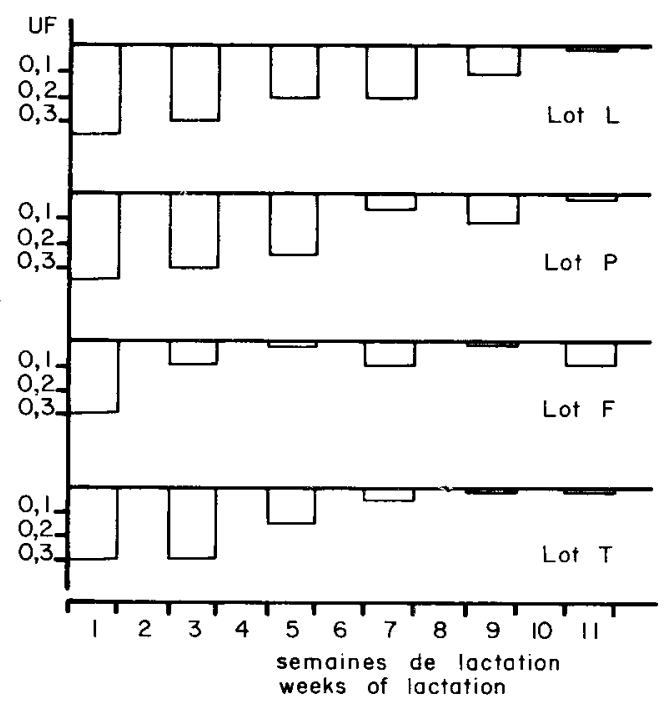

FIG. 4

Evolution du bilan énergétique au cours des onze premières semaines de lactation Variation in the energy balance during the first 11 weeks of lactation 
En définitive, dans nos conditions expérimentales, la substitution du soja par différentes graines protéagineuses (féverole, pois et lupin) dans le concentré pour chèvres laitières dès la mise-bas ne semble pas présenter d'effets défavorables tant sur son appétence que sur la production et la composition du lait.

Accepté pour publication en juin 1981.

\section{Summary \\ Utilization of protein rich seeds in goat diets during early lactation}

A total of 32 goats distributed into 4 groups were used to study the replacement of soybean by protein rich seeds (horse bean, field pea, lupin) in goat diets during early lactation.

The voluntary intake of forage and concentrate were on an average 1500 and 948 g D.M., respectively per day. There was no significant difference in the intake of the four concentrates. Milk production was $3.47 \mathrm{~kg}$ per day. Milk composition was little affected by the nature of the protein supplementation. Only the milk fat level of the "horse bean » group differed significantly $(\mathrm{p}<0.05)$ from the others, while the protein contents were similar.

\section{Références bibliographiques}

Cazes J.P., 1978. Utilisation des graines de pois et de féverole par les ruminants. Perspectives agricoles, 13, 87-92.

Giovanni R., Guilhermet R., Toullec R., 1975. Influence du remplacement du tourteau de soja par la féverole comme principale source de matières azotées dans les aliments concentrés pour veaux d'élevage. Bull. Tech. C.R.Z.V., Theix, I.N.R.A., 19, 6-15.

Hill J.L., ARnold G.W., 1975. The effect of lupinosis on the nutritional value of lupins to sheep. Aust. J. Agric. Res., 26, 923-935.

INGALls J.R., McKirdy J.A., 1974. Fababean as a substitute for soybean meal or rapeseed meal in rations for lactating cows. Can. J. Anim. Sci., 54, 87-89.

Masson C., 1981. Utilisation des graines protéagineuses dans l'alimentation des chèvres laitières. Dans "Nutrition et systèmes d'alimentation de la chèvre», I.T.O.V.I.C.I.N.R.A., Symposium International, Tours, 12-15 mai.

Morand-FeHR P., 1978. Alimentation et composition du lait de chèvre : incidence sur la qualité du fromage. Dans "Données récentes sur l'alimentation de la chèvre», Institut National Agronomique, Paris-Grignon, 211-227.

Pelletier G., Bouchard R., 1978. Evaluation de la féverole et du pois traités ou non traités à la formaldehyde comme source de protéines pour la vache laitière. Can. $J$. Anim. Sci., 58, 659-669.

Sharma H.R., Nicholson J.W.G., 1975. Effects of reating faba beans with formaldehyde or volatile fatty acids on the performance of dairy calves and fistulated sheeps. Can. $J$. Anim. Sci., 55, 705-713.

Tisserand J.L., 1978. Les graines de féverole et de pois dans l'alimentation des ruminants. Fédération Européenne de Zootechnie, $29^{\circ}$ réunion annuelle, Stockholm, 4-9 juin.

Tisserand J.L., Lawrence A., 1979. Utilisation des graines protéagineuses en remplacement du tourteau de soja dans l'alimentation des agneaux. Fédération Européenne de Zootechnie, $30^{\circ}$ réunion annuelle, Harrogate, England, 23-26 juillet. 